\title{
Article \\ Fabrication of Flexible Electrode with Sub-Tenth Micron Thickness Using Heat-Induced Peelable Pressure-Sensitive Adhesive Containing Amide Groups
}

\author{
Hyebeom Shin ${ }^{1}$, Eunseong Yang ${ }^{1,2}$, Yong-Hoon Kim ${ }^{2,3}$, Min-Gi Kwak ${ }^{1}$ and Youngmin Kim ${ }^{1, *}$ \\ 1 Display Research Center, Korea Electronics Technology Institute, 25 Saenariro, Bundang-gu, \\ Seongnam 13509, Korea; hyebeom13@gmail.com (H.S.); didguswjd567@naver.com (E.Y.); \\ kwakmg@keti.re.kr (M.-G.K.) \\ 2 School of Advanced Materials Science and Engineering, Sungkyunkwan University, Suwon 16419, Korea; \\ yhkim76@skku.edu \\ 3 SKKU Advanced Institute of Nanotechnology (SAINT), Sungkyunkwan University, Suwon 16419, Korea \\ * Correspondence: ymkim@keti.re.kr
}

check for updates

Citation: Shin, H.; Yang, E.; Kim, Y.-H.; Kwak, M.-G.; Kim, Y.

Fabrication of Flexible Electrode with Sub-Tenth Micron Thickness Using Heat-Induced Peelable

Pressure-Sensitive Adhesive

Containing Amide

Groups. Nanomaterials 2021, 11, 1250.

https://doi.org/10.3390/nano11051250

Academic Editor: Serge Cosnier

Received: 23 April 2021

Accepted: 7 May 2021

Published: 10 May 2021

Publisher's Note: MDPI stays neutral with regard to jurisdictional claims in published maps and institutional affiliations.

Copyright: (c) 2021 by the authors. Licensee MDPI, Basel, Switzerland. This article is an open access article distributed under the terms and conditions of the Creative Commons Attribution (CC BY) license (https:/ / creativecommons.org/licenses/by/ $4.0 /)$.

\begin{abstract}
In response to the increasing demand for flexible devices, there is increasing effort to manufacture flexible electrodes. However, the difficulty of handling a thin film is an obstacle to the production of flexible electrodes. In this study, a heat-induced peelable pressure-sensitive adhesive (h-PSA) was fabricated and used to manufacture a flexible electrode with sub-tenth micron thickness. Unlike the control PSA, the incorporation of amide groups made the h-PSA fail through adhesive failure at temperatures ranging from 20 to $80^{\circ} \mathrm{C}$. Compared to the peeling adhesion (1719 gf/in) of h-PSA measured at $20^{\circ} \mathrm{C}$, the value $(171 \mathrm{gf} / \mathrm{in})$ measured at $80^{\circ} \mathrm{C}$ was decreased by one order of magnitude. Next, the $8 \mu \mathrm{m}$ thick polyethylene terephthalate (PET) film was attached on a thick substrate $(50 \mu \mathrm{m})$ via $\mathrm{h}$-PSA, and $\mathrm{Mo} / \mathrm{Al} / \mathrm{Mol}$ patterns were fabricated on the PET film through sputtering, photolithography, and wet-etching processes. The thick substrate alleviated the difficulty of handling the thin PET film during the electrode fabrication process. Thanks to the low peel force and clean separation of the h-PSA at $80^{\circ} \mathrm{C}$, the flexible electrode of metal patterns on the PET $(8 \mu \mathrm{m})$ film was isolated from the substrate with little change $(<1 \%)$ in electrical conductivity. Finally, the mechanical durability of the flexible electrode was evaluated by a U-shape folding test, and no cracking or delamination was observed after 10,000 test cycles.
\end{abstract}

Keywords: flexible electrode; sub-tenth micron thickness; heat-induced peelable; pressuresensitive adhesive

\section{Introduction}

Owing to its viscoelastic properties, a pressure-sensitive adhesive (PSA) wets an adherend within a short contact time and deforms to dissipate the applied energy during peeling [1-4]. This enables the PSA to possess high peel strength despite the joint being formed by only a slight pressure. Acrylate-based polymers are widely employed as PSA components because their adhesive properties are easily adjusted by copolymerizing various acrylic monomers [5]. For example, acrylates with low Tg improve the tack property and those with high $\mathrm{Tg}$ increase the cohesive strength [6]. However, the lack of strong intermolecular interactions causes PSA to fail through cohesive failure at high temperatures; thus, remnants of the PSA remain on the adherend. Given that an amide group can be engaged in hydrogen bonding [7], the cohesion force of a PSA is expected to be enhanced by incorporating amide groups in the acrylic polymer. In this study, we synthesized methacryloyl amide (Me-am 2) and used it to produce an acrylate polymer (Ac-am 3) containing amide groups. The structure of Me-am 2 was characterized by FTIR and NMR spectroscopy. Unlike the control PSA, the peel strength of the fabricated h-PSA using Ac-am 3 was high, and it failed adhesively because of intermolecular interactions. 
The amide hydrogen bonding allowed the h-PSA to be cleanly removed from the adherend via adhesive failure even at $80^{\circ} \mathrm{C}$. The viscoelastic properties of the h-PSA were analyzed by measuring the temperature dependence of the storage modulus and $\tan \delta$ using a rheometer.

Flexible electrodes (e.g., graphene composites [8,9], silver composites [10-14], and ionic conductors [15]), which are light, thin, and shapeable, have received much attention as main components for the production of next-generation displays. Given that the thicker the electrode, the more is the applied stress on the electrode, the use of thin films for electrode fabrication is beneficial for securing its mechanical durability [16]. However, the handling of thin films during fabrication processes is challenging because of their poor mechanical property; therefore, thin films should be attached on a thick substrate using PSAs during these processes and then removed from the substrate by peeling when necessary. If the peeling adhesion of the PSA is high, the thin film is torn or wrinkled during peeling, and if the peel force of the PSA is low, the thin film is detached from the substrate during the manufacturing process. Hence, the PSA must have a high peel force to hold the thin film tight during the process and a low peel strength so that the thin film can be released easily by peeling. Although UV-curable PSAs have been used to manufacture flexible electrodes [16], the potential curing of these PSAs by photolithography limits their use [10]. In this study, a heat-induced peelable PSA (h-PSA) was utilized to fabricate a flexible electrode in which metal patterns were formed on an $8 \mu \mathrm{m}$ polyethylene terephthalate (PET) film. Thanks to the combination of low peel force and adhesive failure of the hPSA at $80^{\circ} \mathrm{C}$, the flexible electrode was cleanly detached from the substrate with a slight change $(<1 \%)$ in its electrical properties to produce a sub-tenth micron thick electrode. The mechanical durability of the electrode was evaluated through a U-shape folding test.

\section{Materials and Methods}

\subsection{Materials}

Butyl acrylate, 2-ethylhexyl acrylate, ethyl acrylate, 2-hydroxyethyl acrylate, and triethylamine were purchased from Tokyo Chemical Industry (Tokyo, Japan). Dichloromethane, sodium bicarbonate, magnesium sulfate, celite, and methacryloyl chloride were purchased from Sigma-Aldrich Korea Ltd. (Yongin, Korea). Toluene and ethyl acetate were purchased from Samchun Chemical (Pyeongtaek, Korea), and 2,2-azobisisobutyronitrile (AIBN) was purchased from Junsei Chemical (Tokyo, Japan). All chemicals were used as received without further purification. A silicone-coated polyethylene terephthalate film and a polyethylene terephthalate film were purchased from SKC (Seoul, Korea). A stainless steel (SS) plate was purchased from MMSTECH (Bucheon, Korea).

\subsection{Instrumentations}

${ }^{1} \mathrm{H}$ and ${ }^{13} \mathrm{C}$ NMR spectra were measured on a nuclear magnetic resonance (NMR) spectrometer equipped with Bruker Top Spin 3.2 software (Ascend $500 \mathrm{MHz}$, Bruker, Madison, WI, USA). The Fourier transform infrared (FTIR) spectra in the range of 400 to $4000 \mathrm{~cm}^{-1}$ with a maximum resolution of $0.5 \mathrm{~cm}^{-1}$ were obtained by the attenuated total reflectance method using an FTIR spectrophotometer (IRAffinity-1S, Shimadzu, Kyoto, Japan). The glass transition temperature ( $\mathrm{Tg}$ ) and molecular weights were measured using a DSC-4000 (PerkinElmer, Waltham, MA, USA) with the heating rate of $10^{\circ} \mathrm{C} / \mathrm{min}$ and Agilent 1100 (Agilent, Santa Clara, CA, USA), respectively. The peel strength was measured on a tensile tester (HZ-1007E, MMSTECH, Bucheon, Korea). The viscosity was measured on a DV1 digital viscometer (AMETEK Brookfield, Middleboro, MA, USA). The temperature dependence of the shear storage modulus $\left(G^{\prime}\right)$ and dissipation factor $(\tan \delta)$ was measured in the temperature range of 20 to $80^{\circ} \mathrm{C}$ with a frequency of $1 \mathrm{~Hz}$, a heating rate of $5{ }^{\circ} \mathrm{C} / \mathrm{min}$, and strain of $0.1 \%$ using a rheometer (MCR102, Anton Parr, Graz, Austria). 


\subsection{Synthesis of Methacryloyl Amide 2 (Me-am 2)}

Hydroxyl amide 1 was prepared according to the reported method [17]. A threenecked flask was charged with hydroxyl amide $1(5.0 \mathrm{~g}, 42.7 \mathrm{mmol})$, triethylamine ( $4.45 \mathrm{~g}$, $44.0 \mathrm{mmol}$ ), and dichloromethane (50 g). To this solution methacryloyl chloride (4.46 g, $42.7 \mathrm{mmol}$ ) was slowly added at room temperature. After $20 \mathrm{~h}$ of stirring, methanol was added to the solution. Then, the mixture was poured into a separatory funnel and washed with an aqueous $\mathrm{NaHCO}_{3}$ solution, an aqueous $\mathrm{HCl}$ solution, and deionized water sequentially. An organic layer was collected in a flask, dried over $\mathrm{MgSO}_{4}$, and filtered through celite. The filtrate was concentrated under reduced pressure to afford a methacryloyl amide 2 as a viscous liquid.

${ }^{1} \mathrm{H}$ NMR $\left(400 \mathrm{MHz}, \mathrm{CDCl}_{3}\right)$ : $6.12(\mathrm{~s}, 1 \mathrm{H}), 6.09(\mathrm{bs}, 1 \mathrm{H}), 5.59(\mathrm{~s}, 1 \mathrm{H}), 4.23(\mathrm{t}, 2 \mathrm{H}), 3.34$ (q, 2H), 1.99 (s, 3H), 1.95 (s, 3H), 1.90 (quint, 2H).

${ }^{13} \mathrm{C}$ NMR $\left(100 \mathrm{MHz}, \mathrm{CDCl}_{3}\right) \delta$ : 170.5 (ester $\left.\mathrm{C}=\mathrm{O}\right), 167.5$ (amide $\left.\mathrm{C}=\mathrm{O}\right), 136.2\left(\mathrm{C}=\mathrm{CH}_{2}\right)$, $125.7\left(\mathrm{C}=\mathrm{CH}_{2}\right), 62.3\left(\mathrm{OHCH}_{2}\right), 36.4,28.7,23.1,18.3$.

\subsection{Synthesis of Acrylic Polymer with Amide Functionality (Ac-am 3)}

A three-necked flask $(250 \mathrm{~mL})$ equipped with a stirring bar, a condenser, and an $\mathrm{N}_{2}$-inlet was prepared. To the flask, the following materials were added: butyl acrylate (7.5 g), 2-ethylhexyl acrylate ( $4.5 \mathrm{~g})$, ethyl acrylate ( $2.2 \mathrm{~g})$, 2-hydroxyethy acrylate $(0.62$ $\mathrm{g})$, methacryloyl amide $2(0.78 \mathrm{~g})$, AIBN (0.05 g), ethyl acetate (15 g), and toluene (3.76 g). The flask was immersed in an oil bath and heated at $80^{\circ} \mathrm{C}$. After $6 \mathrm{~h}$ of stirring, a viscous solution containing Ac-am 3 with a solid content of $45 \mathrm{wt} \%$ was obtained.

${ }^{1} \mathrm{HNMR}\left(400 \mathrm{MHz}, \mathrm{CDCl}_{3}\right) \delta: 4.03\left(\mathrm{bs},(\mathrm{CO}) \mathrm{OCH}_{2}\right), 3.78\left(\mathrm{~s}, \mathrm{CH}_{2} \mathrm{OH}\right), 3.48\left(\mathrm{~s},(\mathrm{CO}) \mathrm{NHCH}_{2}\right)$, $2.28(\mathrm{~s},(\mathrm{CO}) \mathrm{CH}), 1.98\left(\mathrm{CH}_{3} \mathrm{NH}(\mathrm{CO})\right), 1.90-0.88$ (aliphatic region).

\subsection{Synthesis of Ac-H}

Acrylic polymer of Ac-H was synthesized through the previously described method using butyl acrylate (7.5 g), 2-ethylhexyl acrylate (4.5 g), ethyl acrylate (2.82 g), 2-hydroxyethy acrylate $(0.78 \mathrm{~g}), \operatorname{AIBN}(0.05 \mathrm{~g})$, ethyl acetate $(15 \mathrm{~g})$, and toluene $(3.76 \mathrm{~g})$ as components.

\subsection{Peeling Adhesion Test}

The as-prepared Ac-am 3 solution was bar-coated on a silicone-coated PET film (release liner), dried at $120^{\circ} \mathrm{C}$ for $2 \mathrm{~min}$, laminated onto a PET film, and kept at $80{ }^{\circ} \mathrm{C}$ for $16 \mathrm{~h}$ to produce an h-PSA tape with a multilayer structure of liner $(50 \mu \mathrm{m}) / \mathrm{PSA}(20 \mu \mathrm{m}) / \mathrm{PET}$ film $(50 \mu \mathrm{m})$. The h-PSA tape was cut into a 1 in wide strip. After the release liner was removed, the h-PSA tape was laminated onto an SS plate and kept at room temperature. After $30 \mathrm{~min}$, the h-PSA/SS plate was placed on a tensile tester, and the h-PSA tape was subjected to a $180^{\circ}$ peel test with a peeling rate of $300 \mathrm{~mm} / \mathrm{min}$ at temperatures of $20,40,60$, and $80^{\circ} \mathrm{C}$.

\subsection{Lap Shear Test}

A lap shear test was performed using a tensile tester [18]. For this, the $20 \mu \mathrm{m}$ thick hPSA was cut to form a $25 \mathrm{~mm} \times 25 \mathrm{~mm}$ piece. Two SS plates measuring $100 \mathrm{~mm} \times 25 \mathrm{~mm}$ were attached with an overlap area of $25 \mathrm{~mm} \times 25 \mathrm{~mm}$ using the h-PSA. Both the ends of the SS plates were fixed in the grips and pulled in the tensile direction with a pulling rate of $0.5 \mathrm{~mm} / \mathrm{s}$ at temperatures of $20,40,60$, and $80{ }^{\circ} \mathrm{C}$. The shear strain rate was calculated as

$$
\text { Shear strain rate }(\%)=\Delta \mathrm{L} / \mathrm{t} \times 100
$$

where $\Delta \mathrm{L}$ is the displacement of the h-PSA, and $\mathrm{t}$ is the thickness.

\subsection{Fabrication of Flexible Electrode}

A schematic of the fabrication of the flexible electrode is shown in Figure 1. After the liner was removed, the h-PSA tape $(7 \mathrm{~cm} \times 7 \mathrm{~cm})$ was laminated onto an $8 \mu \mathrm{m}$ thick PET 
film to afford the structure of PET $(8 \mu \mathrm{m}) / \mathrm{h}$-PSA/substrate. This structure was placed in a DC sputtering system, and layers of molybdenum $(15 \mathrm{~nm})$, aluminum $(200 \mathrm{~nm})$, and molybdenum $(15 \mathrm{~nm}$ ) were sequentially deposited on the PET film in an argon atmosphere. The molybdenum and aluminum were deposited with DC powers of 150 and $300 \mathrm{~W}$, respectively, under a working pressure of $4.6 \times 10^{-3}$ Torr. Next, photoresist patterns were fabricated on the metal multilayer through photolithography, and the exposed metal layer was etched using an acidic solution. Then, the photoresist patterns were removed to produce $\mathrm{Mo} / \mathrm{Al} / \mathrm{Mo}$ patterns on the PET film. The structure of metal patterns $/ \mathrm{PET} / \mathrm{h}$ PSA/substrate was laminated onto a protective film and then kept at $80{ }^{\circ} \mathrm{C}$ for $10 \mathrm{~min}$. Subsequently, the protective film/metal patterns/PET structure was detached from the substrate. Thus, the flexible electrode of metal patterns/PET $(8 \mu \mathrm{m})$ was isolated after the protective film was removed.

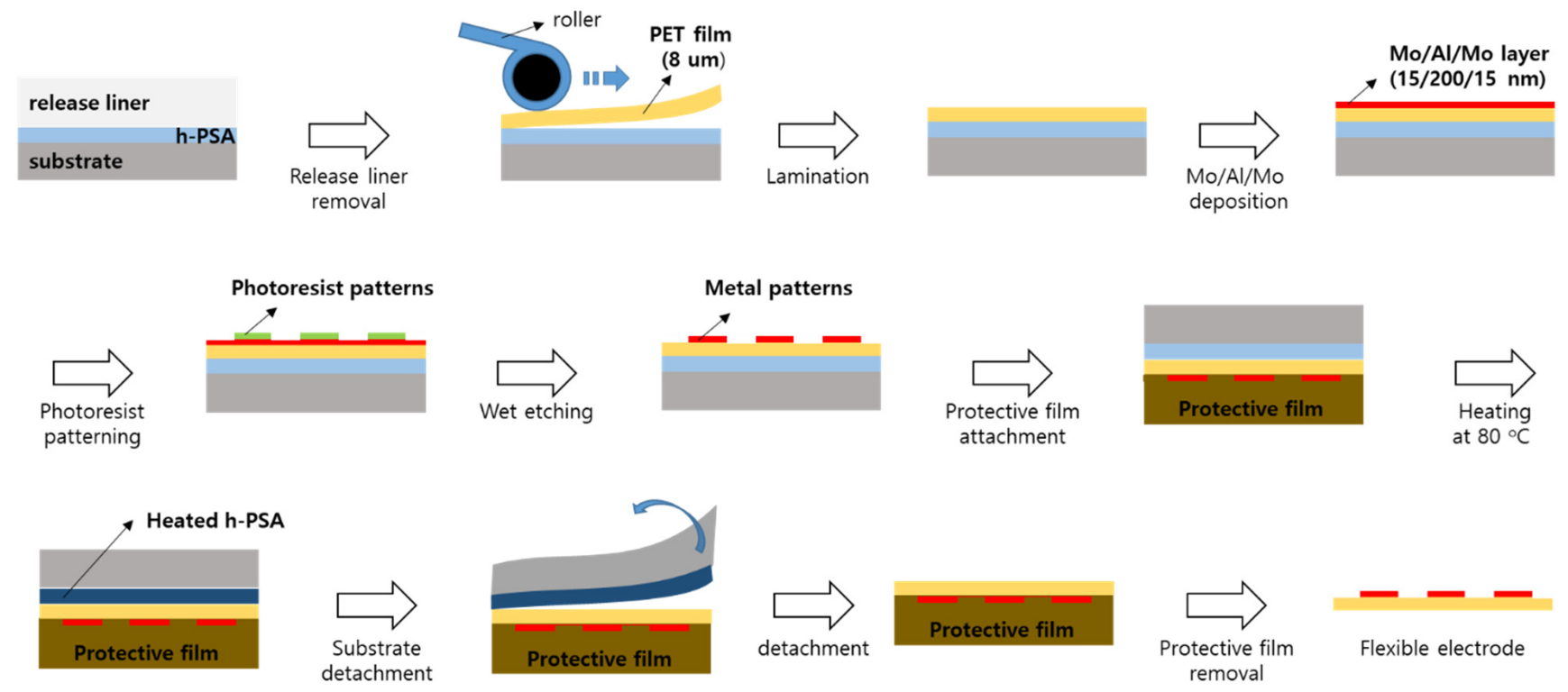

Figure 1. Schematic of the fabrication of the flexible electrode.

\subsection{U-Shape Folding Test}

Both ends of the as-prepared $4 \mathrm{~cm} \times 6.5 \mathrm{~cm}$ electrode were attached on the guide film $(50 \mu \mathrm{m})$, which was adhered to two plates using a Scotch tape (Figure 2a). After the plates were placed in a folding tester, the two plates were repeatedly moved towards each other to fold the electrode into a $U$ shape and moved apart to unfold the electrode (Figure $2 b$ ). For this test, the folding radius, folding rate, and number of folding cycles were $2 \mathrm{~mm}$, 25 cycles/min, and 10,000 cycles, respectively. 
(a)
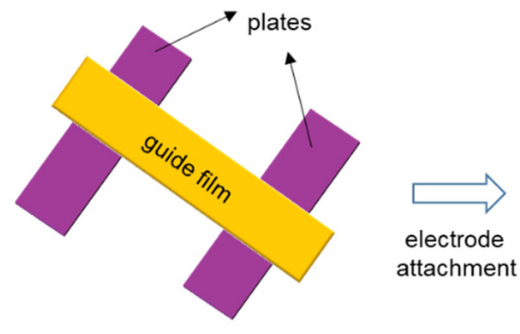
attachment

(b)
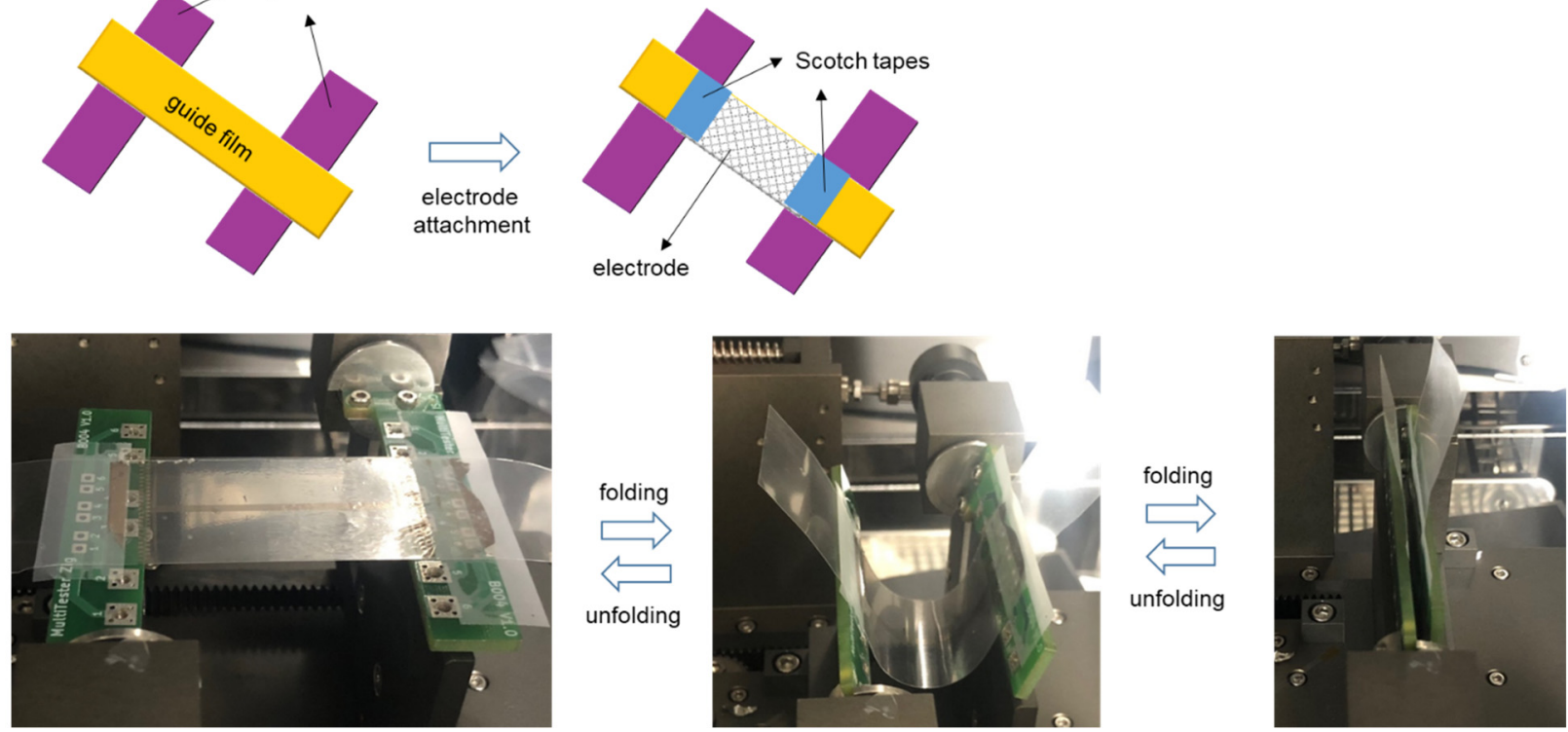

Figure 2. Schematics for (a) preparation of a U-folding test specimen and (b) folded and unfolded electrodes during a U-folding test.

\section{Results}

Because of the balanced cohesion force and free volume [19], PSAs are peeled from adherends with high peel strength via adhesive failure; thus, no debris of the PSA is left on the adherends [20]. However, the lack of strong intermolecular interactions generally causes cohesion failure when PSAs are peeled at high temperature [21]. To overcome this, a methacrylic monomer tethered with an amide group was synthesized and copolymerized with other acrylic monomers to produce a PSA in which intermolecular amide hydrogen bonding was expected.

Firstly, methacryloyl amide (Me-am 2) was synthesized by reacting hydroxyl amide 1 with methacryloyl chloride at room temperature (Scheme 1). The novel compound 2 was characterized by FTIR and NMR spectroscopy. In the FTIR spectrum of Me-am 2, IR absorption for $\mathrm{C}=\mathrm{O}$ stretching of the methacrylate group was observed at $1716 \mathrm{~cm}^{-1}$ (Figure 3) [22]. In addition, the presence of an amide bond in Me-am 2 was ascertained by intense IR absorption at 1647 and $1547 \mathrm{~cm}^{-1}$ corresponding to $\mathrm{C}=\mathrm{O}$ stretching and $\mathrm{N}-\mathrm{H}$ bending, respectively. In comparison to compound 1, the amide I band of compound 2 was shifted to high frequency by $19 \mathrm{~cm}^{-1}$ (Figure $3 \mathrm{a}, \mathrm{b}$ ). This indicates that the amide group of compound 1 is engaged in stronger hydrogen bonding than that of Me-am 2 [23]. This is because the hydrogen atom in the hydroxyl group acts as an H-bond donor, and the oxygen atom in the amide group serves as an H-bond acceptor. The possibility of amidehydroxyl hydrogen bonding has previously been investigated through experiments [23,24] and calculation $[25,26]$. In the ${ }^{1} \mathrm{H}$ NMR spectrum of Me-am 2, proton peaks for the methacryloyl group were observed at 6.12 and $5.59 \mathrm{ppm}$, and a broad proton resonance for $\mathrm{NH}(\mathrm{CO})$ appeared at $6.09 \mathrm{ppm}$. The presence of methacryloyl and amide groups was further confirmed by carbon signals at 170.5 and $167.5 \mathrm{ppm}$ in the ${ }^{13} \mathrm{C}$ NMR spectrum of Me-am 2. The radical polymerization of Me-am 2 was investigated by irradiating the mixture of Me-am 2 and a photoinitiator (Irgacure-184) with UV light. In the FTIR spectrum of the cured Me-am 2, the intensity of the IR absorption at $813 \mathrm{~cm}^{-1}$ for $=\mathrm{C}-\mathrm{H}$ bending decreased, confirming polymerization of the methacryloyl groups (Figure 3c). The thermal behavior of the cured Me-am 2 was observed in the temperature range of -70 to $200{ }^{\circ} \mathrm{C}$ by differential scanning calorimetry (DSC). Two endothermic peaks were observed at -10 and $154^{\circ} \mathrm{C}$, which were assigned as the glass transition temperature $(\mathrm{Tg})$ and melting temperature of the cured Me-am 2, respectively. 

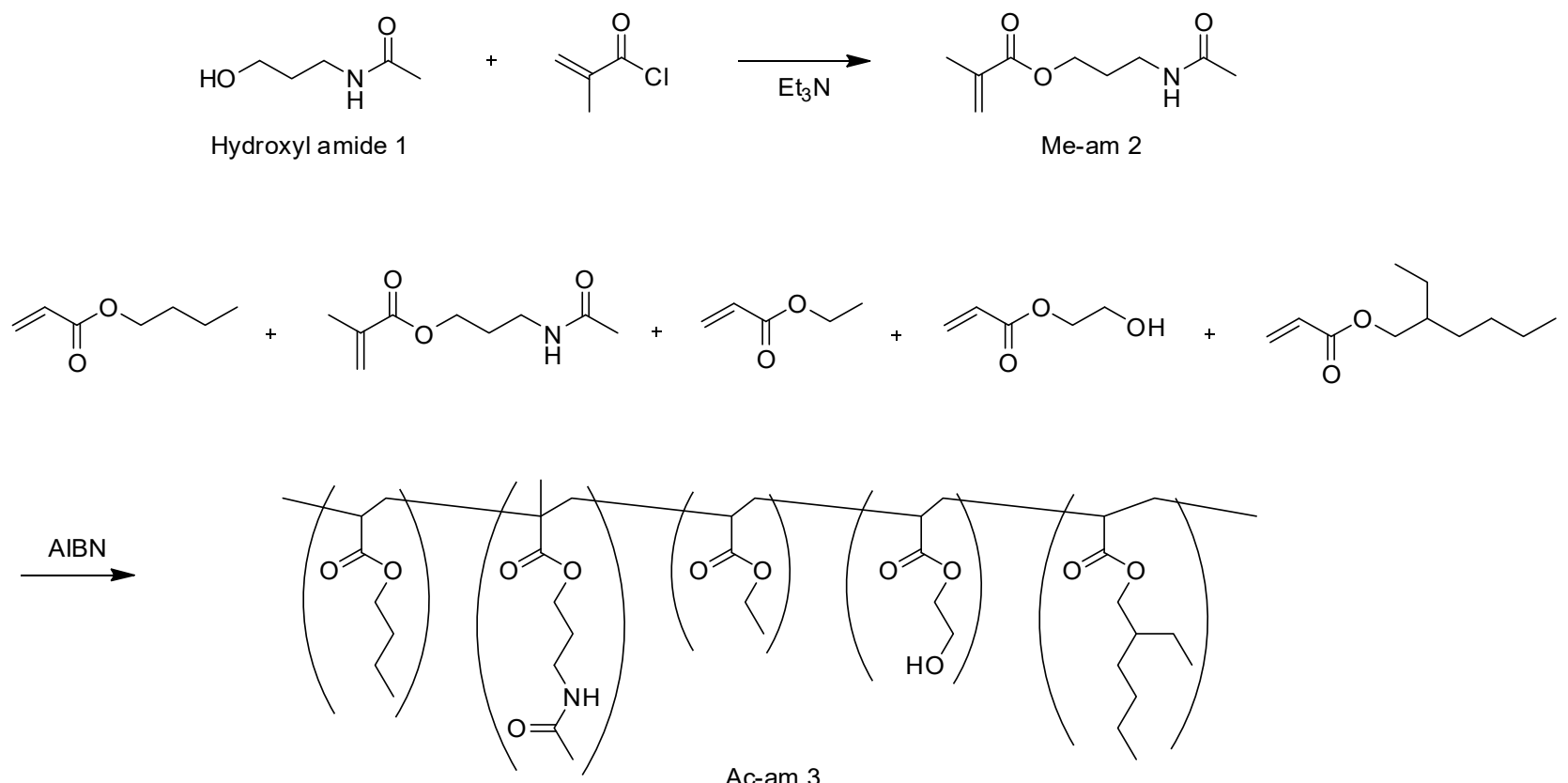

Ac-am 3

Scheme 1. Synthesis of Me-am 2 and Ac-am 3.

\section{$\mathrm{C}=\mathrm{O}$ stretching (amide)}

(a)

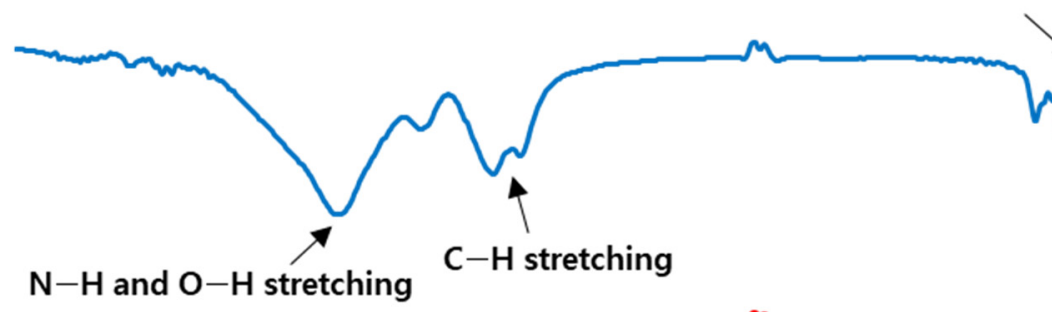

(b)

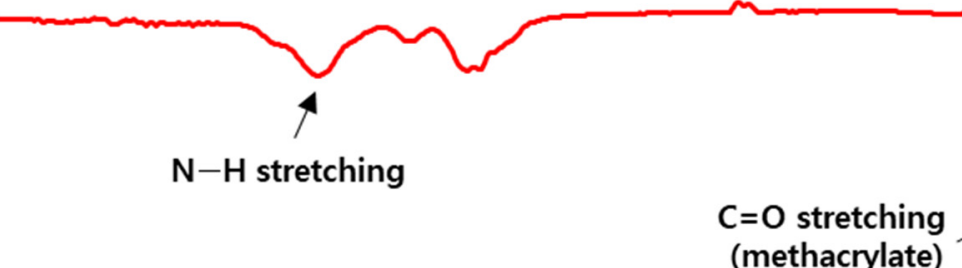

(c)

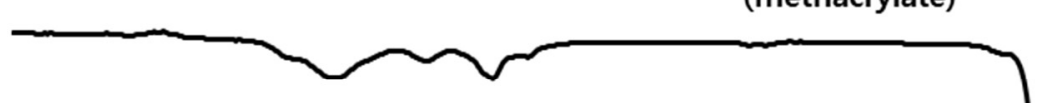

$\mathrm{N}-\mathrm{H}$ bending (amide)
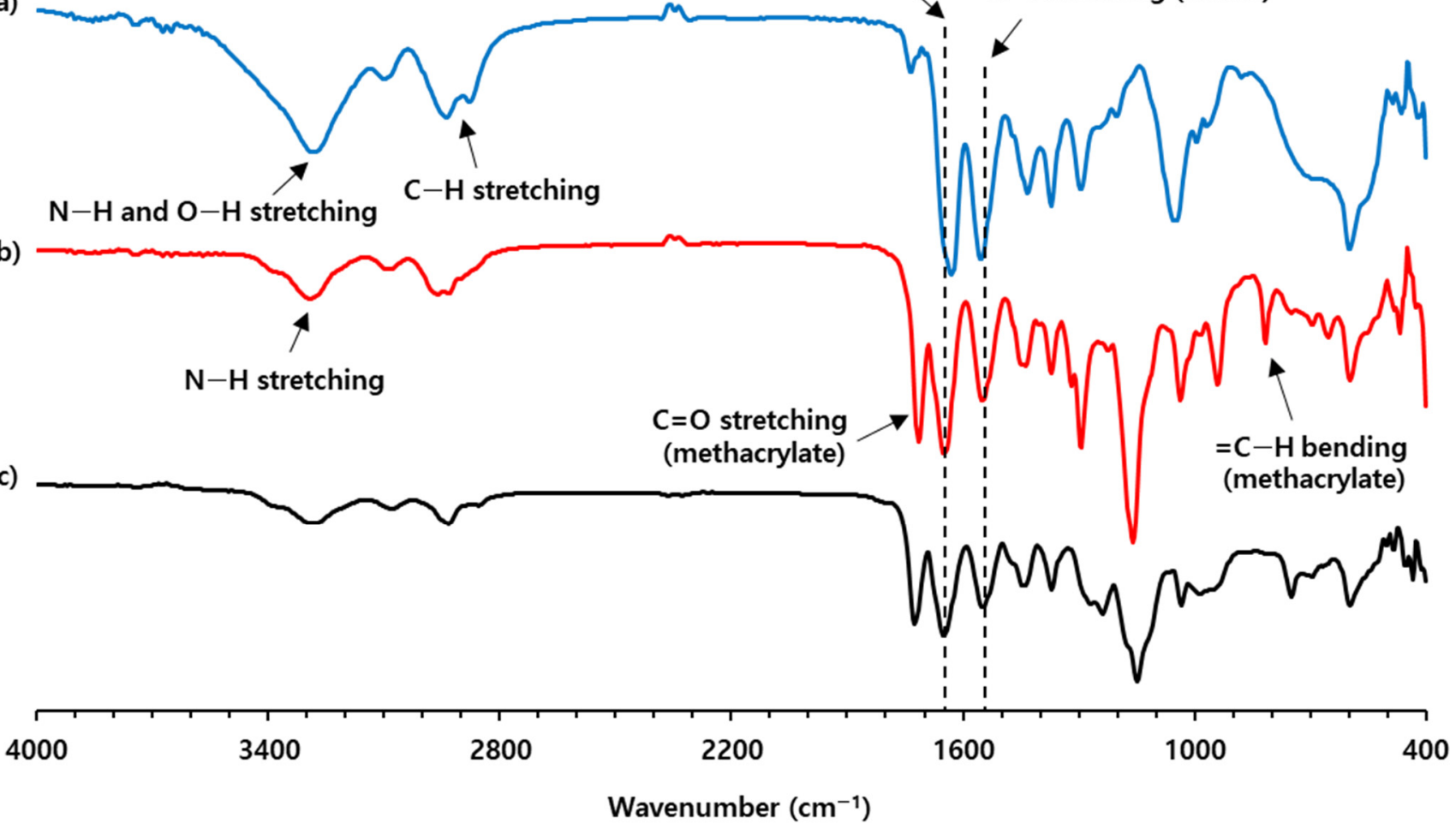

Figure 3. FTIR spectra of (a) hydroxyl amide 1, (b) Me-am 2, and (c) the UV-cured Me-am 2.

With this compound in hand, the acrylic polymer (Ac-am 3) containing amide groups was synthesized (Scheme 1) and used to fabricate the h-PSA. To realize the tack property, acrylic monomers with chain lengths of $\mathrm{C} 4$ to $\mathrm{C} 8$ were used as the main components for synthesizing Ac-am 3. In addition, 2-hydroxyethyl acrylate (HEA) was also employed as a component for the acrylic polymer because strong hydrogen interactions between the hydroxyl groups and the amide groups were expected. Through free-radical polymer- 
ization, an acrylic polymer containing hydroxyl and amide groups was synthesized and isolated. In the ${ }^{1} \mathrm{H}$ NMR spectrum of Ac-am 3, the proton resonances for $\mathrm{CH}_{2} \mathrm{OH}$ and $\mathrm{NH}(\mathrm{CO}) \mathrm{CH}_{2}$ were observed at 3.78 and $3.48 \mathrm{ppm}$, respectively, confirming the incorporation of hydroxyl and amide groups in the acrylate backbone. The viscosity of the solution containing Ac-am 3 with a solid content of $45 \mathrm{wt} \%$ was measured as $4500 \mathrm{cps}$ at $20{ }^{\circ} \mathrm{C}$. The number average and weight average molecular weight of Ac-am 3 were measured to be 56 and $435 \mathrm{~kg} / \mathrm{mol}$, respectively, with a polydispersity index of 7.77. The Tg of Ac-am was $-43{ }^{\circ} \mathrm{C}$ (obtained by DSC), and this value was close to that $\left(-45^{\circ} \mathrm{C}\right)$ calculated by the Fox equation.

Next, the Ac-am 3 solution was bar-coated on a silicone-coated PET film (release film) and dried to produce a $20 \mu \mathrm{m}$ thick h-PSA layer on the release film. Then, a PET film $(50 \mu \mathrm{m})$ was laminated onto the h-PSA layer to produce an h-PSA tape with the structure of release film/h-PSA/PET film. The peeling adhesion of the h-PSA tape was measured as $1719( \pm 60) \mathrm{gf} /$ in at $20^{\circ} \mathrm{C}$. Interestingly, no residue remained on the adherend after detachment, implying that the h-PSA failed adhesively. In comparison, we synthesized an acrylic polymer (Ac-H) without Me-am 2 and used it to fabricate a control PSA. The peel strength of the control PSA was measured as $583( \pm 60) \mathrm{gf} / \mathrm{in}$, and the residual PSA was observed on the adherend after detachment. Given that the PSA without strong intermolecular interactions generally failed cohesively, the amide hydrogen bonding of Acam 3 enabled the h-PSA to be practically usable. Encouraged by this result, we measured the peel strength of the h-PSA tape by a $180^{\circ}$ peel test at various temperatures $(20,40,60$, and $80{ }^{\circ} \mathrm{C}$ ) and analyzed the failure modes. The peel strength of the h-PSA at 40,60, and $80^{\circ} \mathrm{C}$ were measured as $612( \pm 67), 363( \pm 10)$, and $171( \pm 24)$, respectively, and all h-PSAs failed adhesively. The temperature dependence of peeling adhesion is summarized in Table 1 . In comparison to $20^{\circ} \mathrm{C}$, the peeling adhesion of the h-PSA tape was decreased by one order of magnitude at $80{ }^{\circ} \mathrm{C}$ due to the softening of the h-PSA. The softening of the h-PSA was confirmed by a decrease in the storage modulus $\left(\mathrm{G}^{\prime}\right)$ with increasing temperature from 20 to $80{ }^{\circ} \mathrm{C}$ (Figure 4a). However, the dissipation factor ( $\tan \delta$ ) was almost constant and less than 1 in this temperature range (Figure $4 \mathrm{~b}$ ). This indicates that the h-PSA behaved like a viscoelastic solid rather than a liquid even at $80^{\circ} \mathrm{C}$ [27]; thus, the h-PSA failed adhesively. The combination of low peeling adhesion and clean separation made the h-PSA tape peelable at $80^{\circ} \mathrm{C}$.

Table 1. The peel strength and mechanical properties of h-PSA at different temperatures.

\begin{tabular}{cccc}
\hline Temperature $\left({ }^{\circ} \mathbf{C}\right)$ & Peel Strength (gf/in) & $\begin{array}{c}\text { Maximum Strength } \\
\mathbf{( k P a )}\end{array}$ & $\begin{array}{c}\text { Elongation at Break } \\
\left(\mathbf{\%}, \mathbf{1 0}^{\mathbf{3}}\right)\end{array}$ \\
\hline 20 & $1719( \pm 60)$ & $81.1( \pm 4.2)$ & $5.6( \pm 1.3)$ \\
40 & $612( \pm 67)$ & $44.8( \pm 7.0)$ & $12.0( \pm 0.8)$ \\
60 & $363( \pm 10)$ & $24.4( \pm 1.8)$ & $19.3( \pm 4.8)$ \\
80 & $171( \pm 24)$ & $12.1( \pm 3.7)$ & $22.0( \pm 5.8)$ \\
\hline
\end{tabular}

The temperature dependence of the mechanical properties of the h-PSA was investigated (Figure 5), and the results are summarized in Table 1. As the temperature was increased from 20 to $80{ }^{\circ} \mathrm{C}$, the maximum strength of the h-PSA decreased from $81.1( \pm 4.2)$ to $12.1( \pm 3.7) \mathrm{kPa}$, and the elongation at the breaking point increased from $5.6( \pm 1.3) \times 10^{3} \%$ to $22.0( \pm 5.8) \times 10^{3} \%$. The change in mechanical properties with increasing temperature was in good agreement with the storage moduli obtained by the rheometer. 

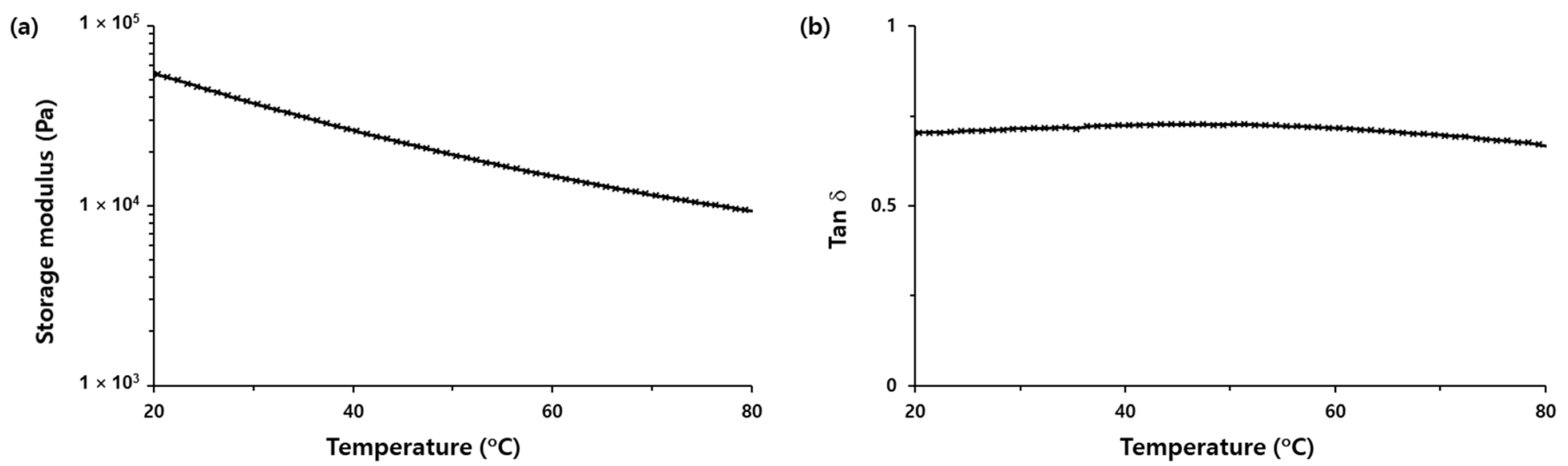

Figure 4. Temperature dependence of (a) storage modulus and (b) $\tan \delta$ of h-PSA.

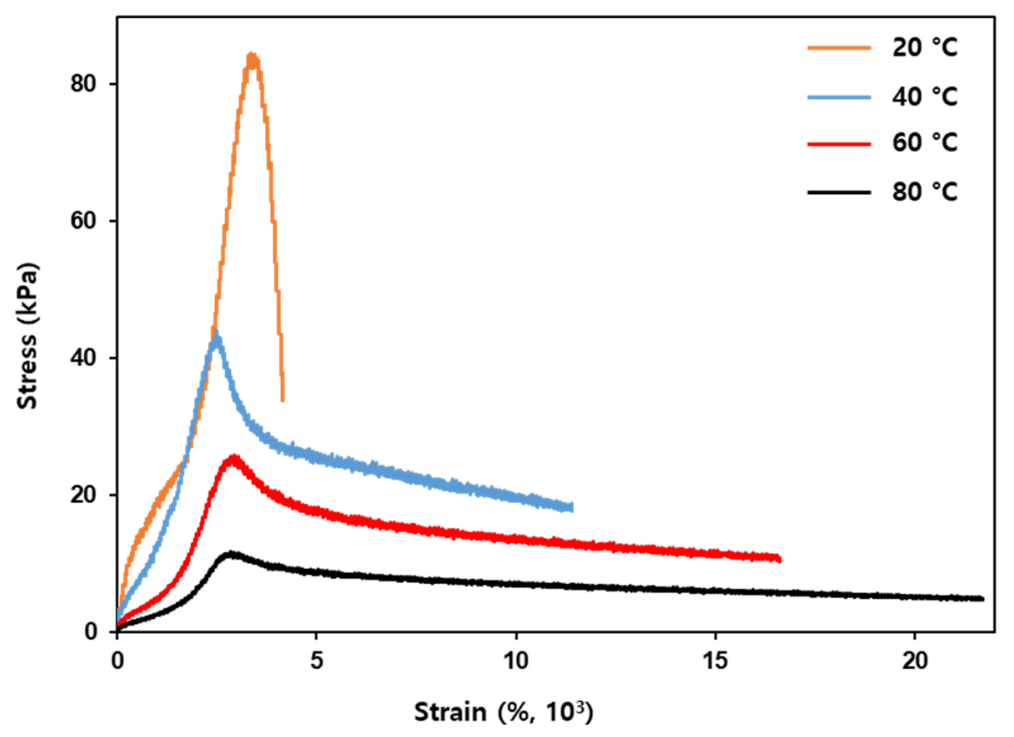

Figure 5. Temperature dependence of stress-strain curves of h-PSA.

Next, a flexible electrode with sub-tenth micron thickness was fabricated using a PSA (Figure 1). Considering the difficulty of handling a thin film $(<10 \mu \mathrm{m})$, it must be fixed on a thick substrate via a PSA during fabrication and separated from the substrate as a free-standing film by peeling. Therefore, the high peel strength of the PSA should be reduced when necessary, and no residue of the PSA should remain on the film after detachment. In this work, h-PSA was utilized to fabricate an $8 \mu \mathrm{m}$ thick flexible electrode (Figure 1). The h-PSA tape was laminated onto an $8 \mu \mathrm{m}$ thick PET film. Then, metal layers of Mo (15 nm), Al (200 nm), and Mo (15 nm) were sequentially deposited on the PET by DC sputtering. The surface resistance of the $\mathrm{Mo} / \mathrm{Al} / \mathrm{Mo}$ multilayer was measured as $0.37( \pm 0.03) \Omega$ /sq. Figure 6 shows the microscopic photos of the surface of the pristine $8 \mu \mathrm{m}$ thick PET film and each metal layer fabricated by sequential sputter deposition. The surface morphology of the metal layers was similar to that of the PET film because the metal layers were too thin $(15-200 \mathrm{~nm})$ to cover the roughened surface of the PET film. Next, metal patterns with a $20 \mu \mathrm{m}$ line width were made on the PET film through photolithography and wet-etching processes (Figure 7). The line resistance of the patterns was determined as $8.89( \pm 0.40) \times 10^{2} \Omega$. Then, the metal patterns on the PET film were laminated onto a protective film to prevent them from being scratched during the peeling process. The structure of protective film/patterned metal layer/PET $(8 \mu \mathrm{m}) / \mathrm{h}-\mathrm{PSA} / \mathrm{substrate}$ was kept at $80^{\circ} \mathrm{C}$ for $10 \mathrm{~min}$ during which the peel strength of the h-PSA was reduced; thus, the structure of the protective film/patterned metal layer/PET $(8 \mu \mathrm{m})$ was readily detached 
from the substrate. After the protective film was removed, the flexible electrode of the patterned metal layer/PET $(8 \mu \mathrm{m})$ was isolated as a free-standing film. The line resistance of the flexible electrode was slightly increased to $8.97( \pm 0.36) \times 10^{2} \Omega$ after detachment, indicating that reduction in the peel strength of the h-PSA at $80{ }^{\circ} \mathrm{C}$ played a key role in the fabrication of the thin electrode through a temporary bonding and debonding process. No cracking or delamination was observed on the surface of the flexible electrode by microscopy (Figure $7 \mathrm{~b}$ ), and this was in good agreement with the little change $(<1 \%)$ in conductivity of the electrode after detachment.

(a)

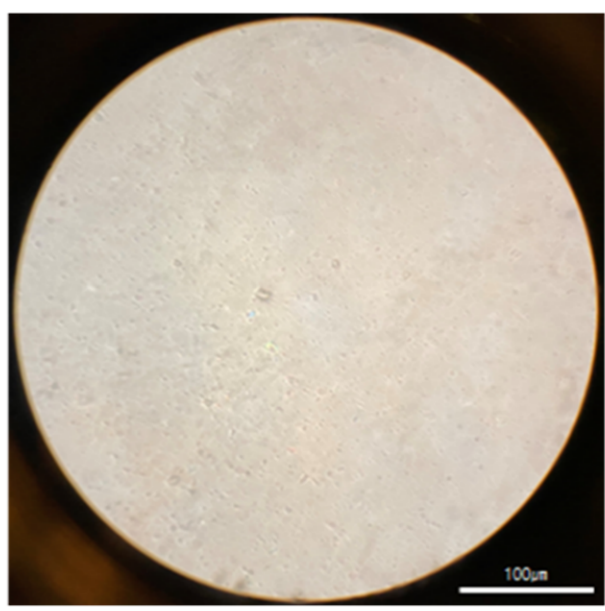

(c)

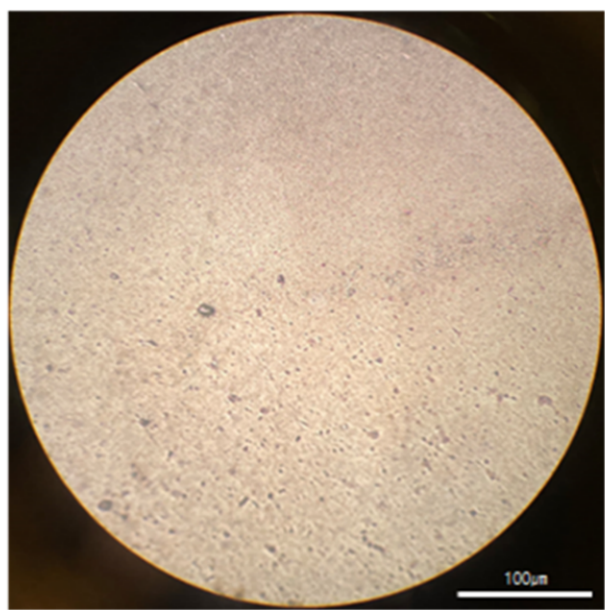

(b)

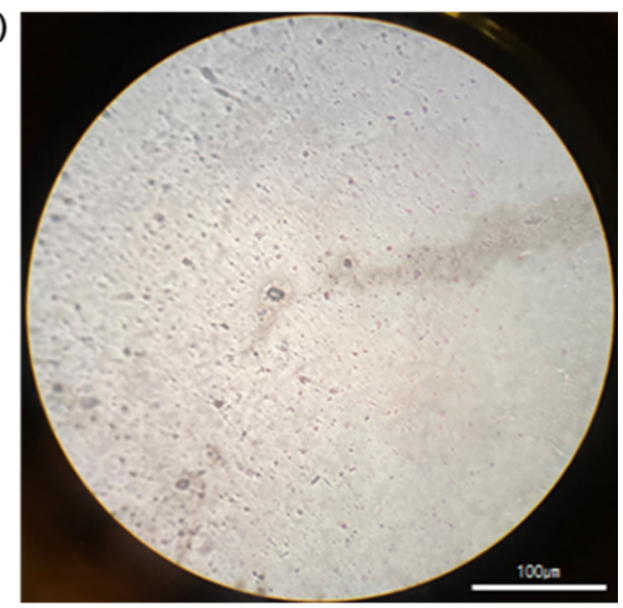

(d)

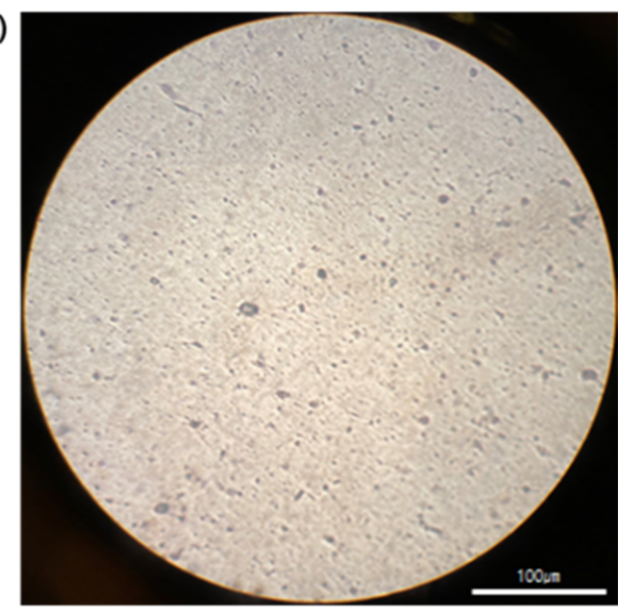

Figure 6. Microscopic images of the surfaces of the (a) PET film, (b) Mo layer in the Mo/PET film, (c) $\mathrm{Al}$ layer in the $\mathrm{Al} / \mathrm{Mo} / \mathrm{PET}$ film, and (d) Mo layer in the $\mathrm{Mo} / \mathrm{Al} / \mathrm{Mo} / \mathrm{PET}$ film.

(a)

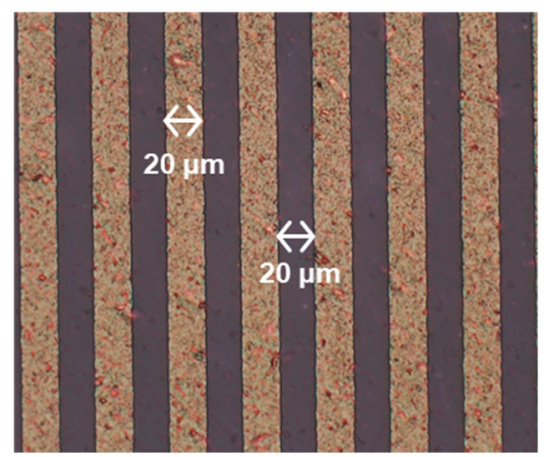

(b)

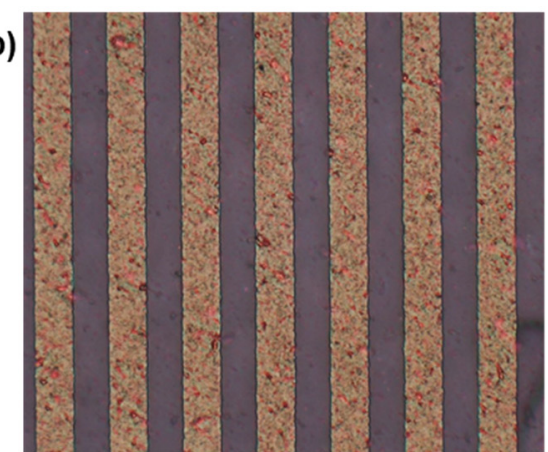

(c)

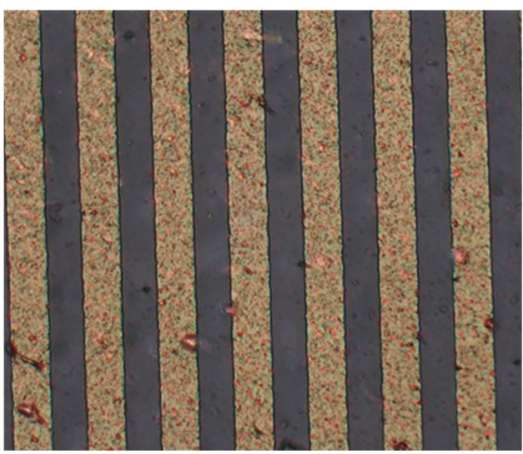

Figure 7. Microscopic images of the metal patterns on the $8 \mu \mathrm{m}$ thick PET film (a) before and (b) after detachment. (c) A microscopic image of the metal patterns of the flexible electrode after 10,000 folding test cycles. 
The mechanical durability of the flexible electrode was evaluated through a U-shape folding test [22]. Both the ends of the electrode were attached on a guide film adhered to two plates using a Scotch tape (Figure 2a). During the folding cycles, the two plates were repeatedly moved towards each other to fold the electrode into a U-shape and moved away from each other to unfold the electrode (Figure $2 b$ ). The folding radius and folding rate for the test were $2 \mathrm{~mm}$ and 25 cycles/min, respectively. The line resistance of the flexible electrode was measured as $9.03( \pm 0.37) \times 10^{2} \Omega$ after 10,000 folding test cycles, implying that the electrode was mechanically durable. No cracking or delamination of the $\mathrm{Mo} / \mathrm{Al} / \mathrm{Mo}$ layers was observed by microscopy (Figure 7c) after numerous folding cycles with a narrow folding radius. This mechanical durability was ascribed to the pliability of the electrode with a sub-tenth micron thickness.

\section{Conclusions}

In this study, amide-tethered methacrylate (Me-am 2) was synthesized and used to fabricate an h-PSA. The amide hydrogen bonding not only endowed the h-PSA with high peel strength (1719 gf/in) but also made it fail adhesively at $20^{\circ} \mathrm{C}$. The peeling adhesion was decreased by one order of magnitude at $80^{\circ} \mathrm{C}$, and no adhesive residue was observed after detachment of the h-PSA. This heat-induced peelable PSA was used to fabricate a flexible electrode through a temporary bonding and deboning process. Thanks to the low peeling strength and clean separation of the h-PSA at $80^{\circ} \mathrm{C}$, the flexible electrode with metal patterns on an $8 \mu \mathrm{m}$ thick PET film was isolated by peeling without damage. The sub-tenth micron thickness made the electrode mechanically durable, and it showed little change in its electrical properties after 10,000 U-shape folding test cycles. Given that electronics are becoming smaller, lighter, and more flexible, the demand for thinner electrodes is increasing. Therefore, the proposed temporary bonding and debonding process employing a heat-induced peelable PSA is expected to be a breakthrough that will enable the production of thin electrodes without damage.

Author Contributions: H.S. carried out fabrication and characterization of the heat-induced pressuresensitive adhesive. E.Y. contributed to manufacturing the flexible electrode. Y.-H.K. and M.-G.K. designed the structure of the flexible electrode and contributed to setting up the evaluation methods. Y.K. designed the PSA compositions, supervised the experiments, and wrote this manuscript. All authors have read and agreed to the published version of the manuscript.

Funding: This work was supported by the Ministry of Trade, Industry, and Energy (MOTIE), Republic of Korea [grant number 20010881, Development of ACF for rigid(COG)/flexible(COP) and secured mass production by developing core material technology for localizing latent hardener for low temperature fast curing].

Institutional Review Board Statement: Not applicable.

Informed Consent Statement: Not applicable.

Data Availability Statement: Data sharing not applicable.

Conflicts of Interest: The authors declare no conflict of interest.

\section{References}

1. Tobing, S.D.; Klein, A. Molecular parameters and their relation to the adhesive performance of acrylic pressure-sensitive adhesives. J. Appl. Polym. Sci. 2001, 79, 2230-2244. [CrossRef]

2. Zosel, A. The effect of fibrilation on the tack of pressure sensitive adhesives. Int. J. Adhes. Adhes. 1998, 18, 265-271. [CrossRef]

3. Fuensanta, M.; Vallino-Moyano, M.A.; Martín-Martínez, J.M. Balanced Viscoelastic Properties of Pressure Sensitive Adhesives Made with Thermoplastic Polyurethanes Blends. Polymers 2019, 11, 1608. [CrossRef] [PubMed]

4. Horgnies, M.; Darque-Ceretti, E.; Felder, E. Relationship between the fracture energy and the mechanical behaviour of pressuresensitive adhesives. Int. J. Adhes. Adhes. 2007, 27, 661-668. [CrossRef]

5. Sohn, S. Various ways to control the bulk properties of pressure sensitive adhesives. J. Adhes. Sci. Technol. 2003, 17, 703-723. [CrossRef]

6. Joo, H.-S.; Do, H.-S.; Park, Y.-J.; Kim, H.-J. Adhesion performance of UV-cured semi-IPN structure acrylic pressure sensitive adhesives. J. Adhes. Sci. Technol. 2006, 20, 1573-1594. [CrossRef] 
7. Czech, Z. Crosslinking of pressure sensitive adhesive based on water-borne acrylate. Polym. Int. 2003, 52, 347-357. [CrossRef]

8. Chang, H.; Wang, G.; Yang, A.; Tao, X.; Liu, X.; Shen, Y.; Zheng, Z. A Transparent, Flexible, Low-Temperature, and SolutionProcessible Graphene Composite Electrode. Adv. Funct. Mater. 2010, 20, 2893-2902. [CrossRef]

9. Liu, N.; Chortos, A.; Lei, T.; Jin, L.; Kim, T.R.; Bae, W.-G.; Zhu, C.; Wang, S.; Pfattner, R.; Chen, X.; et al. Ultratransparent and stretchable graphene electrodes. Sci. Adv. 2017, 3, e1700159. [CrossRef]

10. Ju, Y.H.; Lee, H.-J.; Han, C.J.; Lee, C.-R.; Kim, Y.; Kim, J.-W. Pressure-Sensitive Adhesive with Controllable Adhesion for Fabrication of Ultrathin Soft Devices. ACS Appl. Mater. Interfaces 2020, 12, 40794-40801. [CrossRef]

11. Ju, Y.H.; Lee, H.-J.; Han, C.J.; Lee, C.-R.; Kim, Y.; Kim, J.-W. Water-responsive pressure-sensitive adhesive with reversibly changeable adhesion for fabrication of stretchable devices. Mater. Des. 2020, 195, 108995. [CrossRef]

12. Shin, Y.B.; Ju, Y.H.; Lee, H.-J.; Han, C.J.; Lee, C.-R.; Kim, Y.; Kim, J.-W. Self-Integratable, Healable, and Stretchable Electroluminescent Device Fabricated via Dynamic Urea Bonds Equipped in Polyurethane. ACS Appl. Mater. Interfaces 2020, 12, 10949-10958. [CrossRef] [PubMed]

13. Kim, S.O.; Han, C.J.; Kim, Y.; Kim, K.-S.; Kim, D.U.; Lee, C.-R.; Kim, J.-W. Fabrication of a Bending-Insensitive In-Plane Strain Sensor from a Reversible Cross-Linker-Functionalized Silicone Polymer. ACS Appl. Mater. Interfaces 2020, 12, 6516-6524. [CrossRef] [PubMed]

14. Cao, Y.; Wu, H.; Allec, S.I.; Wong, B.M.; Nguyen, D.-S.; Wang, C. A Highly Stretchy, Transparent Elastomer with the Capability to Automatically Self-Heal Underwater. Adv. Mater. 2018, 30, 1804602. [CrossRef] [PubMed]

15. Cao, Y.; Morrissey, T.G.; Acome, E.; Allec, S.I.; Wong, B.M.; Keplinger, C.; Wang, C. A Transparent, Self-Healing, Highly Stretchable Ionic Conductor. Adv. Mater. 2017, 29, 1605099. [CrossRef]

16. Kim, S.-W.; Ju, Y.H.; Han, S.; Kim, J.S.; Lee, H.-J.; Han, C.J.; Lee, C.-R.; Jung, S.-B.; Kim, Y.; Kim, J.-W. A UV-responsive pressure sensitive adhesive for damage-free fabrication of an ultrathin imperceptible mechanical sensor with ultrahigh optical transparency. J. Mater. Chem. A 2019, 7, 22588-22595. [CrossRef]

17. Pelagalli, R.; Chiarotto, I.; Feroci, M.; Vecchio, S. Isopropenyl acetate, a remarkable, cheap and acylating agent of amines under solvent- and catalyst-free conditions: A systematic investigation. Green Chem. 2012, 14, 2251-2255. [CrossRef]

18. Back, J.-H.; Baek, D.; Sim, K.-B.; Oh, G.-Y.; Jang, S.-W.; Kim, H.-J.; Kim, Y. Optimization of Recovery and Relaxation of Acrylic Pressure-Sensitive Adhesives by Using UV Patterning for Flexible Displays. Ind. Eng. Chem. Res. 2019, 58, 4331-4340. [CrossRef]

19. Park, H.-W.; Seo, H.-S.; Kwon, K.; Lee, J.-H.; Shin, S. Enhanced Heat Resistance of Acrylic Pressure-Sensitive Adhesive by Incorporating Silicone Blocks Using Silicone-Based Macro-Azo-Initiator. Polymers 2020, 12, 2410. [CrossRef]

20. Lee, J.-H.; Lee, T.-H.; Shim, K.-S.; Park, J.-W.; Kim, H.-J.; Kim, Y.; Jung, S. Effect of crosslinking density on adhesion performance and flexibility properties of acrylic pressure sensitive adhesives for flexible display applications. Int. J. Adhes. Adhes. 2017, 74, 137-143. [CrossRef]

21. Moon, S.-h.; Chiche, A.; Forster, A.M.; Zhang, W.; Stafford, C.M. Evaluation of temperature-dependent adhesive performance via combinatorial probe tack measurements. Rev. Sci. Instrum. 2005, 76, 062210. [CrossRef]

22. Lee, H.-J.; Lim, G.; Yang, E.; Kim, Y.-S.; Kwak, M.-G.; Kim, Y. Thermally Conductive Film Fabricated Using Perforated Graphite Sheet and UV-Curable Pressure-Sensitive Adhesive. Nanomaterials 2021, 11, 93. [CrossRef] [PubMed]

23. Zhang, K.; Nelson, A.M.; Talley, S.J.; Chen, M.; Margaretta, E.; Hudson, A.G.; Moore, R.B.; Long, T.E. Non-isocyanate poly(amidehydroxyurethane)s from sustainable resources. Green Chem. 2016, 18, 4667-4681. [CrossRef]

24. Zhang, R.; Li, H.; Lei, Y.; Han, S. Structures and interactions in N-methylacetamide-water mixtures studied by IR spectra and density functional theory. J. Mol. Struct. 2004, 693, 17-25. [CrossRef]

25. Nagaraju, M.; Narahari Sastry, G. Effect of alkyl substitution on H-bond strength of substituted amide-alcohol complexes. J. Mol. Model. 2011, 17, 1801-1816. [CrossRef] [PubMed]

26. Dixon, D.A.; Dobbs, K.D.; Valentini, J.J. Amide-Water and Amide-Amide Hydrogen Bond Strengths. J. Phys. Chem. 1994, 98, 13435-13439. [CrossRef]

27. Lim, D.-H.; Do, H.-S.; Kim, H.-J. PSA performances and viscoelastic properties of SIS-based PSA blends with H-DCPD tackifiers. J. Appl. Polym. Sci. 2006, 102, 2839-2846. [CrossRef] 